\title{
Investigation of Ligustrum lucidum Ait. Seeds Extract as Green Corrosion Inhibitors and Bacteriostatic Agent
}

\author{
Qiang Deng \\ College of Chemistry and Chemical Engineering, Xi'an Shiyou University, Xi'an 710065, China \\ email: deng63@126.com
}

Keywords: Ligustrum lucidum Ait., extract, inhibitor, inhibition efficiency

\begin{abstract}
The extract of Ligustrum lucidum Ait. seeds, as green and eco-friendly corrosion inhibitors, have been investigated on the corrosion inhibition of Q235A steel in $1 \mathrm{M}$ hydrochloric acid solution at $60^{\circ} \mathrm{C}$ by weight loss and potentiodynamic polarisation techniques. The inhibition efficiency of the extracts varies with extract concentration from $10 \mathrm{mg} / \mathrm{L}$ to $1000 \mathrm{mg} / \mathrm{L}$ and the highest one reaches to 95.0\%. The extracts inhibit corrosion mainly by adsorption mechanism. Besides the hydroxyl and ether groups of polyphenols can capture the $\mathrm{H}^{+}$to reduce the corrosion, and the polyphenols can eliminate the dissolved $\mathrm{O}_{2}$ to inhibit the oxygen-adsorption corrosion. Potentiodynamic polarisation studies show that extracts are mixed type inhibitors.
\end{abstract}

\section{Introduction}

During the acidification operation in oilfield, hydrochloric acidic fluid is pumped into wells, which etches the fracture walls irregularly to create highly conductive channels[1]. So it is a challenge for the metal instruments involved. Great attentions have been drown to heat treatment and changing chemical composition to improve its corrosion resistance. But, for the aggressiveness of acidic media, the use of corrosion inhibitors is considered as the most effective method for the protection of many metals against such acid attack [2,3]. Compounds, containing functional electronegative groups and $\mathrm{p}$ and/or $\pi$-electron in triple or conjugated double bonds, are found to be efficient as inhibitors against metal corrosion [3-6]. It has been commonly recognized that an organic inhibitor usually promotes formation of a chelate on a metal surface, by transferring $\mathrm{p}$ and/or $\pi$-electrons from the organic compounds to the metal and forming a coordinate covalent bond during the chemical adsorption[7-10]. Organic compounds, containing heteroatoms, such as sulfur, phosphorus, nitrogen and oxygen, together with aromatic rings in their structure are the major adsorption centers, and the Schiff bases, a condensation product of an amine and a ketone/aldehyde, are such typical molecules [3-10]. Some polydentate Schiff base compounds (PSCs) have been reported as effective corrosion inhibitors for various metals in acid media [11-15].

Ligustrum lucidum (broad-leaf privet, Chinese privet, glossy privet, tree privet or wax-leaf privet) is a species of privet (Ligustrum genus), a flowering plant in the olive family, Oleaceae, native to the southern half of China and naturalized in many places: Spain, Italy, Algeria, Canary Islands, New Zealand, Lesotho, South Africa, Japan, Korea, Australia, Norfolk Island, Chiapas, Central America, Argentina, and the southern United States. The name "Chinese privet" is more frequently used for Ligustrum sinense[16-18]. 

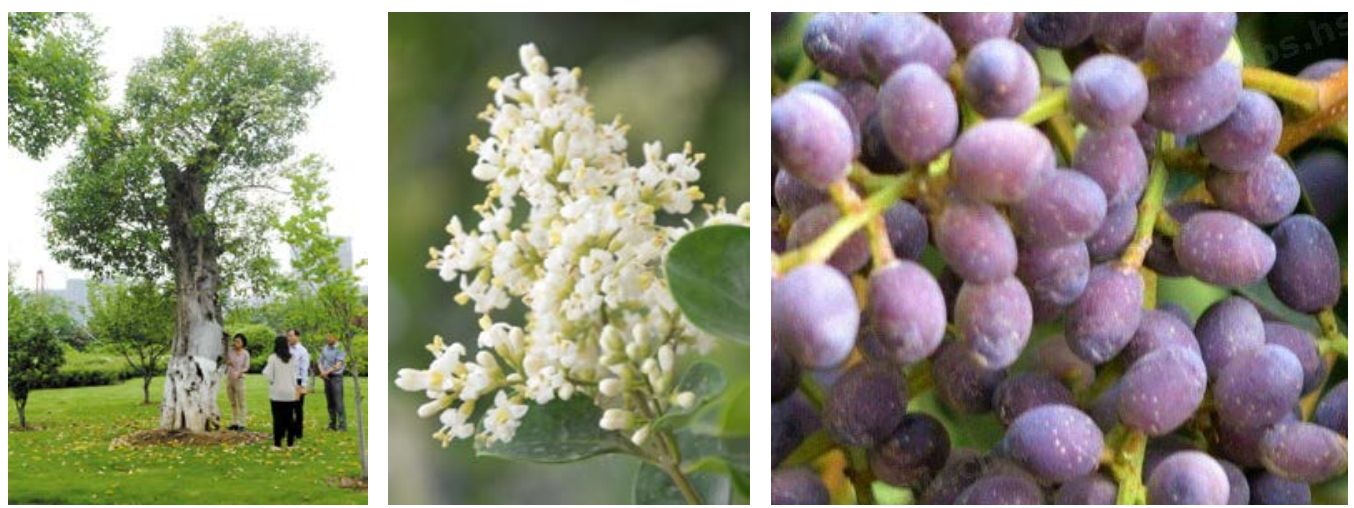

Figure 1 The tree, flower and seeds of Ligustrum lucidum

The seeds are known as Nu-zhen-zi (female chastity seed) in traditional Chinese medicine and are believed to nourish liver and kidney Yin and Jing in the treatment of tinnitus (ringing in the ears), vertigo (dizziness), premature graying of the hair, and soreness/weakness of the lower back and knees. Ligustrum lucidum Ait. has been used in traditional Chinese medicine for over 1000 years because of its anti-tumor, antimutagenic, antidiabetic, and hepatoprotective properties. Due to the belief in the seeds' ability to nourish the liver, they are also used in the treatment of disorders of the eye involving red or dry eyes, blurred vision, and pain. Chemical constituents of the seeds include oleanolic acid(a), nuzhenide(b), and ligustroside(c), as shown in Figure 2 [16-20]. The aim of this work is to investigate the inhibition of Ligustrum sinense seeds extraction as corrosion inhibitors and bacteriostatic agent in oil field.

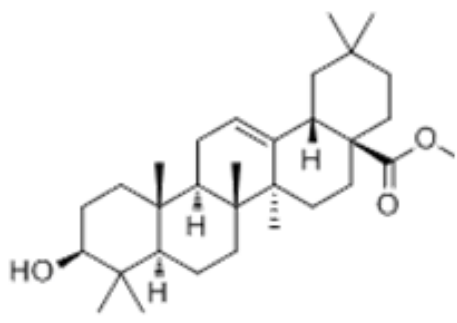

a

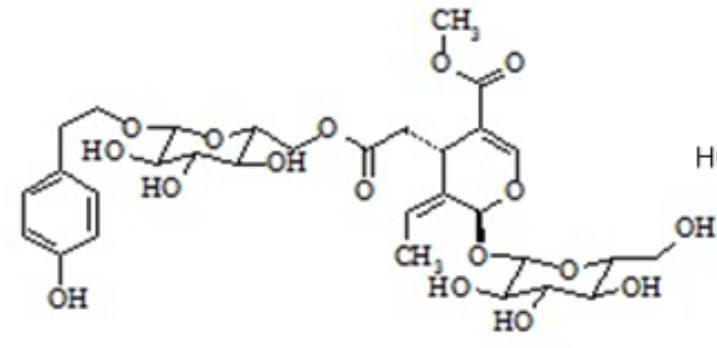

b<smiles>COC(=O)C1=CO[C@@H](O[C@H]2OC(CO)[C@@H](O)C(O)C2O)C2=COC3(OCCc4ccc(O)cc4)CC[C@@]12C3</smiles>

C

Figure 2 Chemical constituents of the Ligustrum sinense seeds

\section{Experiment}

\section{Gravimetric measurements.}

The corrosion tests were performed on Q235A with a composition (in wt.\%) C: 0.22, P: 0.045, Si: 0.35 , S: $0.05, \mathrm{Mn}: 1.40$, and Fe balance. The electrolyte solution was $1 \mathrm{M} \mathrm{HCl}$, prepared from analytical grade $38 \% \mathrm{HCl}$ and distilled water. The concentration range of Ligustrum lucidum Ait. seeds extract (LSE) was employed as $50 \mathrm{mg} / \mathrm{L}$ to $1000 \mathrm{mg} / \mathrm{L}$. All tests have been performed in deaerated solutions. The gravimetric tests were carried out according to the People's Republic of China Standard of Petroleum and Natural Gas Industry (Evaluation method for behavior of corrosion inhibitor for produced water of oilfield, SY/T5273-2000) with a few modifications. Each test was done with three specimens at the same time to give reproducible results.

\section{Microbiological monitoring.}

Viable counts of SRB, TGB and FB were determined with the "most probable number" method, People's Republic of China Standard of Petroleum and Natural Gas Industry, the national method of the bactericidal agent's performance, SY/T 5890-1993). The produced water containing the three kinds of bacteria was gathered from Zichang Oilfield Factory, Yanchang Oilfield. 


\section{Results and Discussion}

\section{Acidic corrosion inhibition.}

The inhibition efficiency (IE) of Ligustrum lucidum Ait. seeds extract (LSE) was investigated in the concentration range from $10 \mathrm{mg} / \mathrm{L}$ to $500 \mathrm{mg} / \mathrm{L}$ in $1 \mathrm{M} \mathrm{HCl}$; changes of IE (\%) with the inhibitor concentration are summarized in Table 1 . It can be inferred from the Table 1 that LSE exhibits obviously good corrosion-inhibition effect on Q235A steel, and the inhibition efficiency (IE) is rising as the concentration increasing. Increase in inhibition efficiencies with the concentration of LSE shows that the inhibition actions may due to its adsorption on the steel surface $[11,12]$.

\begin{tabular}{ccc} 
Table 1 The inhibition efficiency of LSE measured by weight loss \\
\hline Extract & $\begin{array}{c}\text { Concentration } \\
(\mathrm{mg} / \mathrm{L})\end{array}$ & $\begin{array}{c}\text { Inhibition Efficiency } \\
(\%)\end{array}$ \\
\hline LSE & 10 & 20.1 \\
LSE & 20 & 44.5 \\
LSE & 50 & 62.5 \\
LSE & 100 & 85.0 \\
LSE & 200 & 86.4 \\
LSE & 500 & 88.5
\end{tabular}

Changes of the IE (\%) under different temperature with different concentration are shown in Figure 3. For the concentration $1000 \mathrm{mg} / \mathrm{L}$, the inhibition efficiency increase with the temperature, which reach to $88.5 \%$ in $1 \mathrm{M} \mathrm{HCl}$ under $30^{\circ} \mathrm{C}$. But it shows different for the concentration lower than $100 \mathrm{mg} / \mathrm{L}$. The results imply that we should change the concentration of the inhibitor with the temperature.

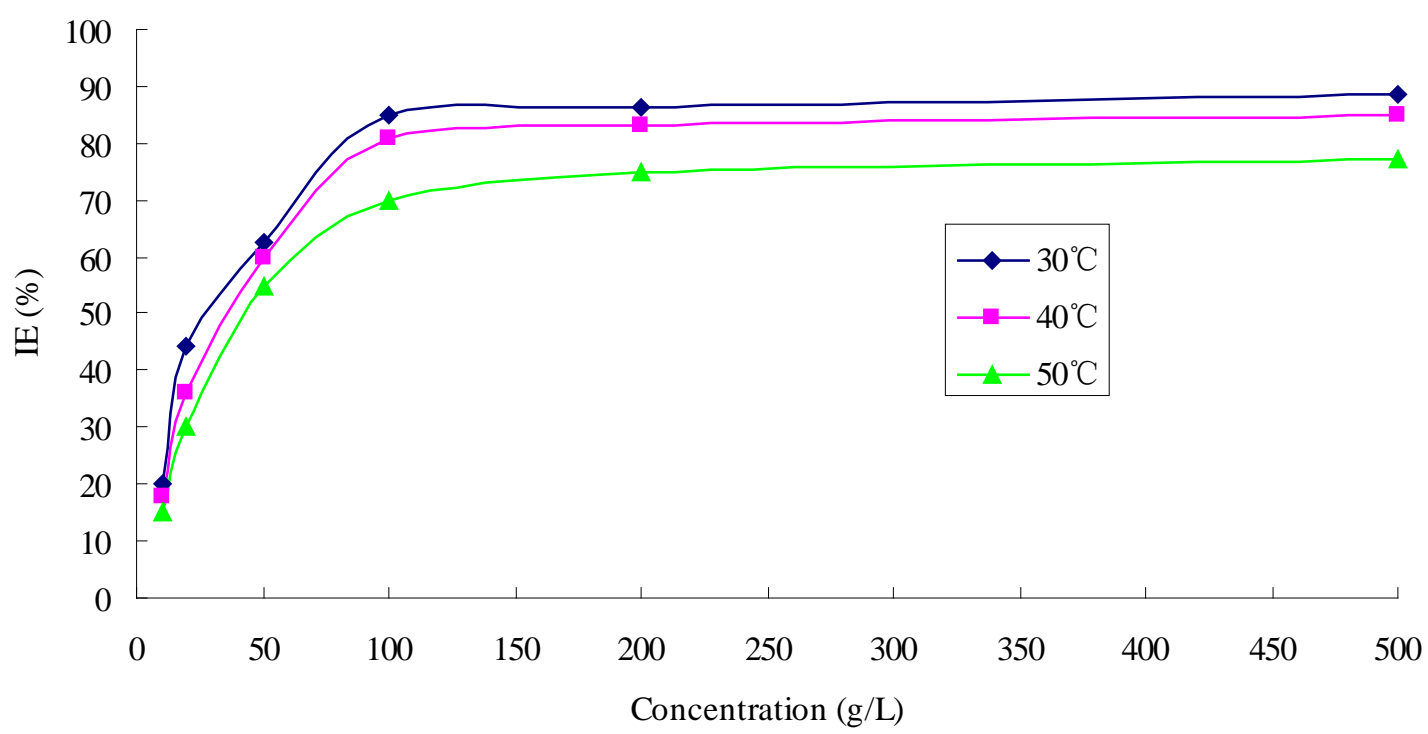

Figure 3 The inhibition efficiency of LSE under different temperature

The corrosion-inhibition effect can be explained on the basis of additive adsorption. It is well recognized that organic inhibitor molecules set up their inhibition action via the adsorption onto the metal/solution interface. The adsorption process is affected by the chemical structures of the inhibitors, the nature and charged surface of the metal and the distribution of charge over the whole inhibitor molecule. The presence of $\mathrm{N}, \mathrm{O}, \mathrm{S}$ atoms and conjugated double bonds in the organic structures makes the formation of $\mathrm{p}-\mathrm{d}$ bonds resulting from overlap of p-electrons to the $3 \mathrm{~d}$ vacant 
orbital of iron atoms, which enhances the adsorption of the compounds on the metal surface [13-16]. In general, organic inhibitor molecules may be adsorbed on the metal surface in one or more of the following ways [13-16]:

(a) electrostatic interaction between the charged molecules and the charged metal;

(b) interaction of unshared electron pairs in the molecule with the metal;

(c) interaction of p-electrons with the metal;

(d) a combination of types (a-c).

The electron rich phenol groups and aromatic rings of polyphenols extract from pomegranate means it is easy to coordinate with the iron and form a protective film (as shown in Figure 4). The hydroxyl groups and ether groups of polyphenols, with abundant $p$-electrons, can capture the $\mathrm{H}^{+}$, which reduce the concentration and corrosive of $\mathrm{HCl}$ solution. The polyphenols can be oxidized to benzoquinone by the $\mathrm{O}_{2}$ resolved in the solution, by which inhibit the oxygen-adsorption corrosion<smiles></smiles>

Figure 4 The absorption of ellagic acid on the ion surface by coordination

\section{Bioactivity.}

Corrosion is an electrochemical process leading to the deterioration of materials that can be caused or accelerated by microbiological activity, so called Microbiologically Influenced Corrosion (MIC). It is estimated that $30-50 \%$ of the corrosion cases are a result of microbial activity. MIC caused by growth of sulfate reducing bacteria (SRB), iron bacteria (IB) and total general bacteria (TGB) in oil pipelines, is considered a major problem for water treatment in the oil industry. MIC can result in different types of attack: pitting, crevices, dealloying and erosion in pipelines[25]. Corrosion products produced by microorganisms are production of hydrogen sulfide, molecular hydrogen, hydrogen ions and destabilization of metal oxide films. In addition, microbial degradation of crude oil can lead to increased acidity in the oil phase, and oil containing acids is a problem concerning corrosion of pipelines. The reported results showed that the interaction of IB, SRB and TGB accelerated the corrosion rate, and the corrosion in the mixture of IB, SRB and TGB was more serious than in a single microbial system. If this is the case, different treatment system to inhibit corrosion should be considered, among which bactericide agent has received the greatest acceptance. Currently, oxidizer, aldehyde, quatemary ammonium salt and heterocycle compounds has been used as bactericide agents, and $\mathrm{Cl}_{2}, \mathrm{ClO}_{2}$, formaldehyde, pentane-1,5-dial, trichloroisocyanuric acid (TCCA) and ect, but the toxicity tests have been conducted on a limited selection. The antifungal activity of LSE against oilfield microorganism was tested under the concentration of $50 \mathrm{mg} / \mathrm{L}$ to $1000 \mathrm{mg} / \mathrm{L}$, and the results were summarized in Table 2. From the table, it can be found that LSE is antifungal active against TGB and IB, but not so active against SRB. 
Table 2 The antifungal activity of LSE against oil field MIC

\begin{tabular}{cccc}
\hline $\begin{array}{c}\text { Concentration } \\
\mathrm{mg} / \mathrm{L}\end{array}$ & \multicolumn{3}{c}{ Microbiotic Concentration $/ \mathrm{mL}$} \\
SRB & IB & TGB \\
\hline- & 110.0 & 110.0 & 110.0 \\
50 & 70 & 70 & 70 \\
100 & 70 & 25 & 25 \\
200 & 25 & 6 & 6 \\
500 & 25 & 6 & 6 \\
1000 & 25 & 6 & 6 \\
\hline
\end{tabular}

\section{Conclusion}

The inhibition of Ligustrum lucidum Ait. seeds extract and the mechanism on the corrosion of high protective Q235A steel in $\mathrm{HCl}$ solution were scree ned and discussed. It can inhibit the corrosion with moderate inhibition efficiency in different conditions and the highest reaches to $83.2 \%$ with the concentration of $1000 \mathrm{mg} / \mathrm{L}$ in $1 \mathrm{M} \mathrm{HCl}$ solution. Besides, it displays potent activity against the oilfield water-borne bacteria, especially for SRB and IB.

\section{Acknowledgment}

This work was financially supported by the grants from National Science Foundation of China (21376189) and Scientific and Technological Plan Projects of Shaanxi Province (2014TG-09).

\section{References}

[1] Borchardt J.K., Yen T.F.: Oil-Field Chemistry-Enhanced recovery and production stimulation, Toronto, Ontario, Canada, 1988, 608-610.

[2] Liu Y.R., Gao Z.M., Zhang Z., Shi D.F.: Electrochemically aided deposition of $\mathrm{TiO}_{2}$ films on Ni-P pre-plated A3 carbon steel, Corrosion Science and Protection Technology, 2007, 19, 323-325.

[3] Jiang J.H., Li L., Hu J.X., Jiang J.Q., Ma A.B.: New Zinc-phosphating process with RE catalyzer at low temperature for painting pretreatment of cold-rolling A3 steel sheet, Surface Technology, 2007, 36(4), 79-81.

[4] Sastri V.S.: Corrosion inhibitors principle and application, John Willey \& Sons, New York, 1998, 198-202.

[5] Raman A., Labine P., Quraishi M.A.: Reviews on corrosion inhibitor science and technology, NACE International, Houstan, 2004, 3.

[6] Cizek A.: Acidizing inhibitors, Materials Performance, 1994, 33, 56-61.

[7] Cruz J., Martinez R., Genesca J., Ochoa E.G.: Experimental and theoretical study of 1-(2-ethylamino)-2-methylimidazoline as an inhibitor of carbon steel corrosion in acid media, Journal of Electroanalytical Chemistry, 2004, 566, 111-121.

[8] Huang Y.X., Cai J., Zhou J.M.: Corrosion inhibition of magnolia leaf extracts in acid medium for A3 steel, Applied Chemistry Industrial, 2010, 39, 538-540.

[9] Pan M.Z., Cai J., Yu M.: Corrosion inhibition of Gum leaves extracts in acid medium for A3 steel, Chemical Engineering, 2012, 2, 70-72. 
[10]Zhao S.R., Xu G.D., Liao X.Q.: Preliminary study on the extracts of pine apple waste as corrosion inhibitor and their inhibiting properties to A3 steel in H2SO4 solution, Chemical Cleaning, 1996, 12(2), 4-6.

[11]Tang Y.P., Lou F.C., Wang J.H., Li Y.F., Zhuang S.F.: Coumaroyl flavonol glycosides from the leaves of Ginkgo biloba, Phytochemistry, 2001, 58, 1251-1256.

[12]vanDijk C., Driessen A.J., Recourt K.: The uncoupling efficiency and affinity of flavonoids for vesicles, Biochemical Pharmacology, 2000, 60, 1593-1600.

[13]Varga E.: The protective effect of EGb 761 in isolated isochemical/ reperfused rat hearts, Acta Pharmaceutica Hungarica, 2002, 72, 265-271.

[14] Stanislav J., Shahid M., Koji N.: Isolation of ginkgolides A, B, C, J and bilobalide from G. biloba extracts, Phytochemistry, 2004, 65, 2897-2902.

[15]Issaadi S., Douadi T., Zouaoui A., Chafa S., Khan M.A., Bouet G.: Novel thiophene symmetrical Schiff base compounds as corrosion inhibitor for mild steel in acidic media, Corrosion Science, 2011, 53, 1484-1488.

[16]Hegazy M.A.: A novel Schiff base-based cationic gemini surfactants: Synthesis and effect on corrosion inhibition of carbon steel in hydrochloric acid solution, Corrosion Science, 2009, 51, 2610-2168.

[17]Wang ZX, Gao BZ, Xu BY, Huang GC. Study on antimutagenic effect of Ligustrum lucidum Ait. by drosophila test. Fujian J. Traditional Chin. Med. 1991, 22: 50-51.

[18]Yin, Y.S., and Yu, C.S. Study on chemical components and hepatoprotective properties of Ligustrum lucidum Ait. Chin. Traditional Patent Med. 1993, 15: 18-19.

[19]Dawei Gao, Qingwang Li, Ying Li, Zhihua Liu, Zhiwei Liu, Yusheng Fan, Zengsheng Han, Jian Li, Kun Li. Antidiabetic potential of oleanolic acid from Ligustrum lucidum Ait. Canadian Journal of Physiology and Pharmacology, 2015, 85(11): 1076-1083.

[20]Ma ZX, Pu JZ, Sun ZY. The extracts method oleanolic acid from Ligustrum lucidum Ait. [Chinese]. Acta Acad. Med. Zunyi, 2003, 26: 474-475. 